\title{
RECEIVING VECTORS OF MUON TELESCOPE OF COSMIC RAY STATION NOVOSIBIRSK
}

\author{
V.L. Yanchukovsky ${ }^{1}$, V.G. Grigoryev ${ }^{2}$, G.F. Krymsky ${ }^{2}$, V.S. Kuzmenko ${ }^{1}$, A.D. Molchanov ${ }^{1}$ \\ ${ }^{1}$ Geophysical Survey SB RAS, \\ Novosibirsk, Russia,vjanch@gs.sbras.ru \\ ${ }^{2}$ Yu.G. Shafer Institute of Cosmophysical Research and Aeronomy SB RAS, Yakutsk, Russia
}

The method of receiving vectors allows us to determine cosmic ray anisotropy at every moment of time. Also, the method makes it possible to study fast anisotropy fluctuations related to the interplanetary medium dynamics. Receiving vectors have been calculated earlier for neutron monitors and muon telescopes. However, most muon telescopes of the network of cosmic ray stations for which calculations were made does not operate now. In recent years, new, improved detectors have been developed. Unfortunately, the use of them is limited because of the absence of receiving coefficients. These detectors include a matrix telescope in Novosibirsk. Therefore, receiving vector components for muon telescopes of observation cosmic ray station Novosibirsk have been defined. Besides, design features of the facility, its orientation, and directional diagram depending on zenith and azimuth angles were taken into account. Also, for the system of telescopes, we allowed for coupling coefficients found experimentally by the test detector.

Keywords: cosmic rays, muons, telescope, receiving vectors.

\section{INTRODUCTION}

Receiving vectors have previously been calculated for neutron monitors [Mori, 1968a; Yasue et al., 1982; Grigoryev, Chirkov, 1978] and muon telescopes [Mori, 1968b; Grigoryev et al., 2007]. Most muon telescopes of the network of cosmic ray (CR) stations for which the receiving vectors were computed are not operating now. In recent years, a number of new, modernized detectors have been developed. Unfortunately, their usage is limited for lack of receiving coefficients for them. Among these detectors is a matrix telescope in Novosibirsk. A multichannel observation CR complex (MOCRC) in Novosibirsk [Yanchukovsky, 2010] functionally includes a neutron monitor 24NM-64, a spectrograph based on the effect of local generation of neutrons [Yanchukovsky, Yanchukovsky, 1982; Yanchukovsky, Filimonov, 2000], and the matrix muon telescope [Yanchukovsky, 2006a]. The matrix structure provides an individual CR station with a whole system of multi-directional muon telescopes. Being special-purpose, muon telescopes are more suitable to observe CR anisotropy than neutron monitors. It is necessary to 
determine $\mathrm{CR}$ anisotropy and gradients with energy 1-250 GeV in order to devise methods for diagnostics of interplanetary medium, using ground-based CR observations. The global survey method worked out by IKFIA SB RAS [Krymsky et al., 1966] enables us to identify CR anisotropy at every instant of time and to study fast anisotropy fluctuations related to interplanetary medium dynamics. It combines three methods [Belov et al., 2004]:

- a coupling coefficient method [Dorman, 1957];

- a method for trajectory calculations of particle motion in the geomagnetic field [Dorman et al., 1971];

- a method of spherical analysis allowing us to determine spherical harmonics for further analysis [Kolmogorov, Fomin, 1989].

Harmonic coefficients are coefficients of receiving vectors for CR detectors and a vector characterizing $\mathrm{CR}$ anisotropy in interplanetary space.

\section{METHOD OF RECEIVING VECTORS}

The CR intensity detected by a device in the atmosphere depends on its receiving characteristics representing the geometry and geographical location of the device and a type of observable secondary particles. To take into account effects of these parameters, IKFIA SB RAS developed a method of receiving vectors [Kuzmin, 1968].

The distribution of CR over a sphere $I(\theta, \varphi)$ outside the magnetosphere can be presented as a series expansion in a system of spherical functions being solutions of Laplace's equation:

$$
I(\theta, \varphi)=\sum_{n=0}^{\infty} \sum_{m=0}^{n}\left(a_{n}^{m} \cos (m \varphi)+b_{n}^{m} \sin (m \varphi)\right) P_{n}^{m}(\sin \varphi),
$$

where $\theta, \varphi$ are latitude and longitude angles in a coordinate system, $P_{n}^{m}(\sin \varphi)$ are associated Legendre functions. It is convenient to represent this distribution as a multidimensional vector $\vec{A}=\left\{a_{n}^{m}, b_{n}^{m}\right\}$ with an infinite number of components 0 th $\leq m \leq n \leq \infty$. Then for each point device we can identify a receiving vector $\vec{R}$ such that the $\mathrm{CR}$ intensity $I$, registered by the device, is equal to the scalar product:

$$
I=\vec{A} \vec{R} .
$$

From these equations it follows that

$$
\begin{aligned}
& \vec{R}=\left\{x_{n}^{m}, y_{n}^{m}\right\}, \text { where } x_{n}^{m}=\cos (m \varphi) P_{n}^{m}(\sin \varphi) \\
& y_{n}^{m}=\sin (m \varphi) P_{n}^{m}(\sin \varphi) .
\end{aligned}
$$

To find receiving vectors for real devices, we have to know directional diagrams of a detector $N(\theta$, $\varphi$ ), coupling coefficients $W(E)$ between secondary and primary particles, energy spectrum $f_{n}(E)$ of CR variations under study, and asymptotic angles of arrival $\Psi(E, \theta, \varphi), \Phi(E, \theta, \varphi)$. Cosmic ray distributions expanding in spherical functions, the series converges rapidly. Therefore, along with the isotropic component, the first two harmonics of distribution with experimentally observed effects are usually taken 
into consideration. Accordingly, in vectors $\vec{A}$ and $\vec{R}$ we account for the first nine components.

Receiving vectors are calculated below for the MOCRC of multi-directional narrow-angle muon telescopes in Novosibirsk. CR muons are registered using detecting matrices implemented on the basis of gas-discharged proportional counters CGM-14 [Yanchukovsky, 1994]. The particles are separated according to direction of arrival through four-fold coincidence of signals in four rows of counters by two over and under the neutron monitor (Figure 1).

The counters, combined into detector blocks of three each, are arranged mutually perpendicular and, being included into coincidence circuits, form $45 \times 45 \mathrm{~cm}$ detection areas (Figure 2).

Directions utilized to compute receiving vectors of muon telescopes based on the gas-discharged counters are determined by coincidence circuits and orientation of a device. For the complex of muon telescopes of Yakutsk spectrograph, the following directions have been selected: vertical and zenith angles of $30^{\circ}, 60^{\circ}$ from north and south [Grigoryev et al., 2007]. The CR observation complex of muon telescopes in Novosibirsk with the matrix method for detection based on four-fold coincidences being adopted enables us to detect particles in vertical and at zenith angles of $26,35,44,55$, and $63^{\circ}$. Yet azimuth directions of registration for the zenith angles depend on the orientation of a section of the neutron monitor, the telescope is placed on, and can be northward (N), southward (S), westward (W), eastward (E), as well as NW, WS, SE, and EN.

\section{DIRECTIONAL DIAGRAMS}

Each device when recording $\mathrm{CR}$ is oriented to a celestial region defined by its directional diagram $N(\theta$, $\varphi) d \omega$ with $\omega$ being a solid angle [Kuzmin, 1964]. The directional diagram represents both geometric features of the device and the zenith-azimuth angular dependence of intensity of detected particles [Kuzmin, 1968].

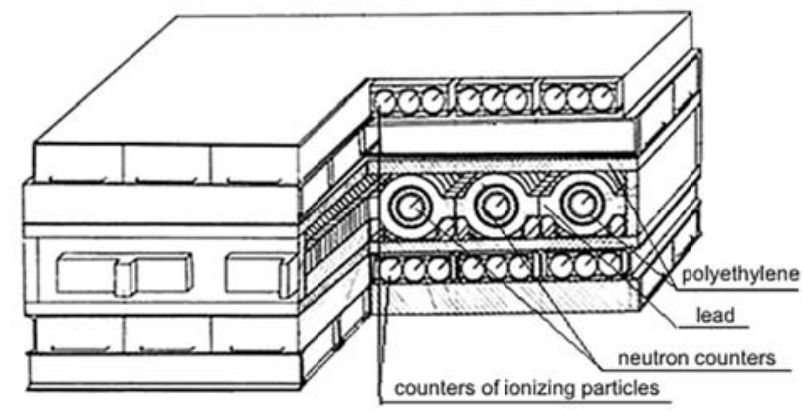

Figure 1. Location of ion counters of the telescope in a section of the neutron monitor
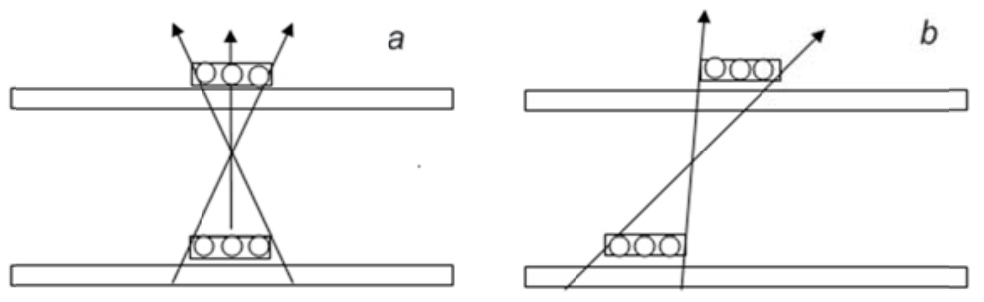

Figure 2. Schematic diagram of four-fold coincidences in recording particles from a vertical direction $(a)$ and 
from a direction of $26^{\circ}$ from the vertical $(b)$

The angular dependence of CR intensity is defined by the following equation

$I(\theta)=I_{0} \cos ^{\gamma} \theta$

where $I_{0}$ is the absolute intensity of vertically arriving particles that is $0.5 \mathrm{~cm}^{-2} \mathrm{~min}^{-1} \mathrm{sr}^{-1}$ [Murzin, 1970], $\gamma$ is the exponent of angular distribution of particles (for Earth's surface $\gamma=1.3$ ). Then the muon telescope count rate $N_{\text {count }}$ is found as

$$
N_{\text {count }}=I_{0} C \text {, }
$$

where $C$ is called the telescope luminosity [Kuzmin, 1968] and is defined by

$$
C=\int_{0}^{\varphi} \int_{0}^{\theta} S(\theta, \varphi) \cos ^{\gamma+1} \theta \sin \theta d \varphi d \theta
$$

Here $S(\theta, \varphi)$ is an area crossed by particles with coincidences being registered in a chosen direction, depending on zenith $\theta$ and azimuth $\varphi$ angles of their arrival. The exponent $\gamma$ in (6) depends on the height of observation relative to Earth's surface. The side of a detector square cell $L=45 \mathrm{~cm}$, and the distance between bottom and top layers of cells, set for coincidence, $H=103 \mathrm{~cm}$ (Figure 2). The directional diagram for one detector block is calculated for directions of registration at zenith angles of $0,26,44,55$, and $63^{\circ}$. Expected count rates (without regard to the mass of the neutron monitor) are estimated for different zenith angles of the muon telescope. The front location of the neutron monitor in a direction of $30^{\circ} \mathrm{NW}$ is taken as $0^{\circ}$ azimuth angle.

DIRECTION FOR REGISTRATION OF PARTICLES AT A ZENITH ANGLE OF $0^{\circ}$ (VERTICAL)

The area $S(\theta, \varphi)$ crossed by particles with coincidences being registered from a vertical direction for one detector block is found as

$$
S(\theta, \varphi)=(L-H \operatorname{tg} \theta \cos \varphi)(L-H \operatorname{tg} \theta \sin \varphi)
$$

where, on condition of coincidences, each factor in brackets cannot be less than zero. When calculating a directional diagram, the angle to start integration is determined by the type of the diagram - azimuth or zenith. For luminosity of the telescope recording vertically arriving particles we have

$$
C_{\text {верт }}=\int_{0}^{\pi / 2} \int_{0}^{\pi / 2} S(\theta, \varphi) \cos ^{\gamma+1} \theta \sin \theta \cos \theta d \theta d \varphi .
$$

Additional $\cos \theta$ accounts for a corner between the surface of the top layer of detector matrix and the direction of incident particles. The telescope designed to record vertically arriving particles collects particles from all azimuths; in this case $C_{\text {vert }}$ is multiplied by 4 . Given $I_{0}$, obtain the count rate of one block $N_{\text {vert }}=10026 \mathrm{pulse} / \mathrm{hr}$. Then the count rate of the telescope comprising 24 blocks (one section of the facility) $N_{\text {vert }}^{24}=240624$ pulse $/ \mathrm{hr}$. 


\section{DIRECTION FOR REGISTRATION OF PARTICLES AT ZENITH ANGLES}

\section{OF 26, 44, 55, and $63^{\circ}$}

For the said zenith angles, let us consider azimuth directions of $30^{\circ} \mathrm{NW}, 30^{\circ} \mathrm{WS}, 30^{\circ} \mathrm{SE}, 30^{\circ} \mathrm{EN}$. The area $S(\theta, \varphi)$, crossed by particles with coincidences being recorded, for oblique directions of the telescope consists of two parts:

$$
S(\theta, \varphi)=S_{1}(\theta, \varphi)+S_{2}(\theta, \varphi),
$$

where $S_{1}(\theta, \varphi)=(H \operatorname{tg} \theta \cos \varphi-r)(L-H \operatorname{tg} \theta \sin \varphi), \theta \leq \theta_{T}$;

$$
S_{2}(\theta, \varphi)=\left(r_{1}-H \operatorname{tg} \theta \cos \varphi\right)(L-H \operatorname{tg} \theta \sin \varphi), \theta \geq \theta_{T} .(11)
$$

Here $\theta_{T}$ is a zenith angle of telescope axis (direction); $r, r_{1}$ are the shortest and longest distances in a horizontal plane between sides of upper and lower cells set for coincidence. For $\theta_{T}=26,44,55$, and $63^{\circ}$, we have $r=5,55,105$, and $155 \mathrm{~cm}, r_{1}=95,145,195$, and $245 \mathrm{~cm}$ respectively.

According to the above calculation procedure for the count rate of the telescope detecting vertically arriving particles, we obtained expected count rates for angled telescopes $N_{\theta_{T}}^{n}$ (here $n$ is the total number of cell pairs, set for coincidence, for the angled telescope at a zenith angle $\theta_{T}$ ):

$$
\begin{aligned}
& N_{26}^{20}(\mathrm{NW}, \mathrm{SE})=130700 \mathrm{pulse} / \mathrm{hr} ; \\
& N_{26}^{18}(\mathrm{WS}, \mathrm{EN})=117630 \mathrm{pulse} / \mathrm{hr} ; \\
& N_{44}^{16}(\mathrm{NW}, \mathrm{SE})=35060 \mathrm{pulse} / \mathrm{hr} ; \\
& N_{44}^{12}(\mathrm{WS}, \mathrm{EN})=26300 \mathrm{pulse} / \mathrm{hr} ; \\
& N_{55}^{12}(\mathrm{NW}, \mathrm{SE})=7800 \mathrm{pulse} / \mathrm{hr} ; \\
& N_{55}^{6}(\mathrm{WS}, \mathrm{EN})=4000 \mathrm{pulse} / \mathrm{hr} ; \\
& N_{63}^{8}(\mathrm{NW}, \mathrm{SE})=1710 \mathrm{pulse} / \mathrm{hr} .
\end{aligned}
$$

In brackets are azimuth directions of the telescopes. Figure 3 shows zenith and azimuth directional diagrams for vertical and angled directions of the system of muon telescopes included into the MOCCR.

\section{COUPLING COEFFICIENTS}

Coupling coefficients $W$, according to the definition offered by Dorman [Dorman, 1957], characterize relative sensitivity of a detector to protons of primary cosmic rays with different energies. Coupling coefficients for channels of the matrix muon telescope included into the MOCRC were found through theoretical calculations [Yanchukovsky, 1986] and experimentally [Yanchukovsky, 2006b; Yanchukovsky, 2007] through the method of test detector [Dvornikov et al., 1989]. The coupling coefficients normalized to $100 \%$ were determined as 


$$
W\left(E, \theta_{T}\right)=a \frac{\exp \left\{-d[E \alpha+b]^{-c}\right\}}{[E \alpha+b]^{c+1}},
$$

where $a$ is a normalization coefficient calculated as

$$
a^{-1}=\int_{E_{\min }}^{\infty} \frac{\exp \left[-d(\alpha E+b)^{-c}\right]}{(\alpha E+b)^{c+1}} d E .
$$

Here and in (12), the $b, c, d$, and $\alpha$ parameters, normalization coefficient $a$, and threshold energy $E_{\min }$ are functions of $\theta_{T}$ (a zenith angle of telescope axis $T$ ). The $b, c, d$, and $\alpha$ parameters were gauged by the method for functional minimization [Yanchukovsky, 2007]. We calculated numerical values of the coupling coefficients from Equation (12). Hereafter, the calculations involve a certain discrete set of energies - from the threshold $E_{\min }\left(\theta_{T}\right)$ for each direction $\theta_{T}$ of particle detection to energies of around $1000 \mathrm{GeV}$. The findings (after normalizing and taking into account the screen thickness in the directions) are plotted in Figure 4.

\section{COSMIC-RAY TRAJECTORIES}

CR trajectories for the station Novosibirsk were computed for the same discrete set of energies that was employed to calculate the coupling coefficients. Directional diagrams of the muon telescopes also being a function of azimuth angle (Figure 3), asymptotic angles of arrival $\Psi(E, \theta, \varphi), \Phi(E, \theta, \varphi)$ were calculated with a resolution of $8^{\circ}$ in zenith (from $0^{\circ}$ to $64^{\circ}$ ) and $10^{\circ}$ in azimuth (from $0^{\circ}$ to $350^{\circ}$ ). Yet, we used coefficients of expansion of the main geomagnetic field represented by 10 harmonics for the epoch of 2000s [ftp://nssdcftp.gsfc.nasa.gov/models/geomagnetic/igrf/ fortran_code]. The CR trajectories were determined by the method described in [Dorman et al., 1971]. In numerical integration, we applied the Eulerian method with the initial step $h_{0}$ selected empirically according to the solution accuracy.
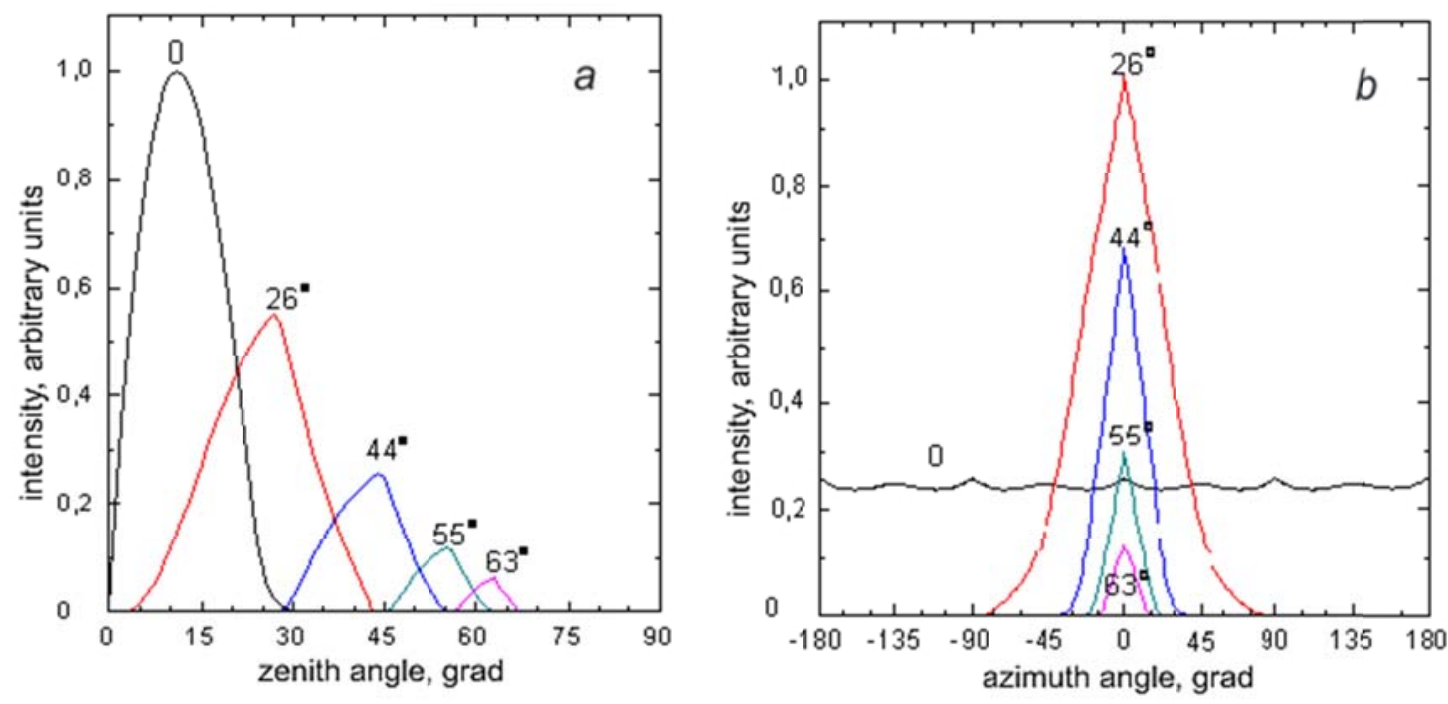

Figure 3. Zenith (a) and azimuth (b) directional diagrams of the complex of muon telescopes at zenith angles of $0,26,44,55$, and $63^{\circ}$ 


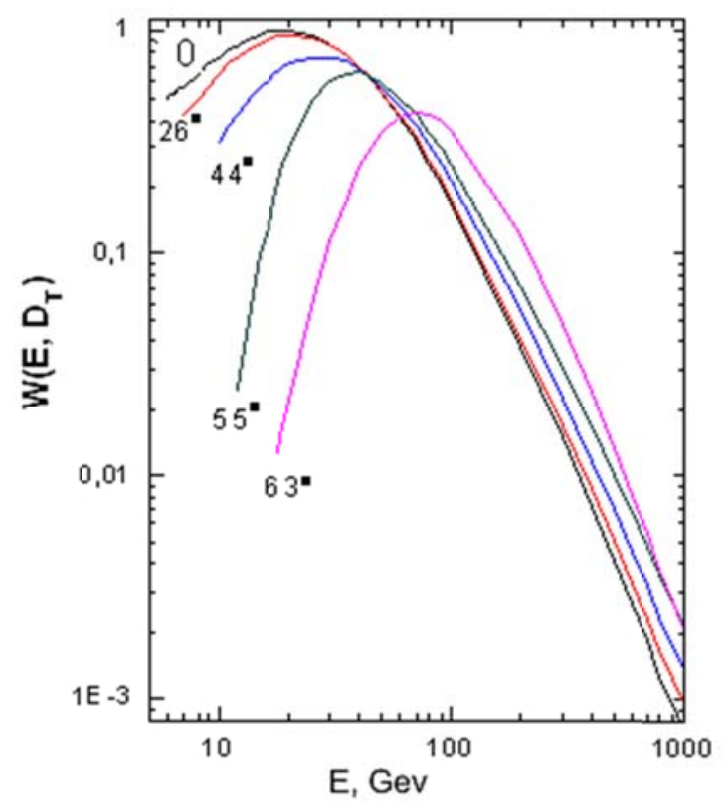

Figure 4. Coupling coefficients $W\left(E, \theta_{T}\right)$ for the MOCRC of muon telescopes
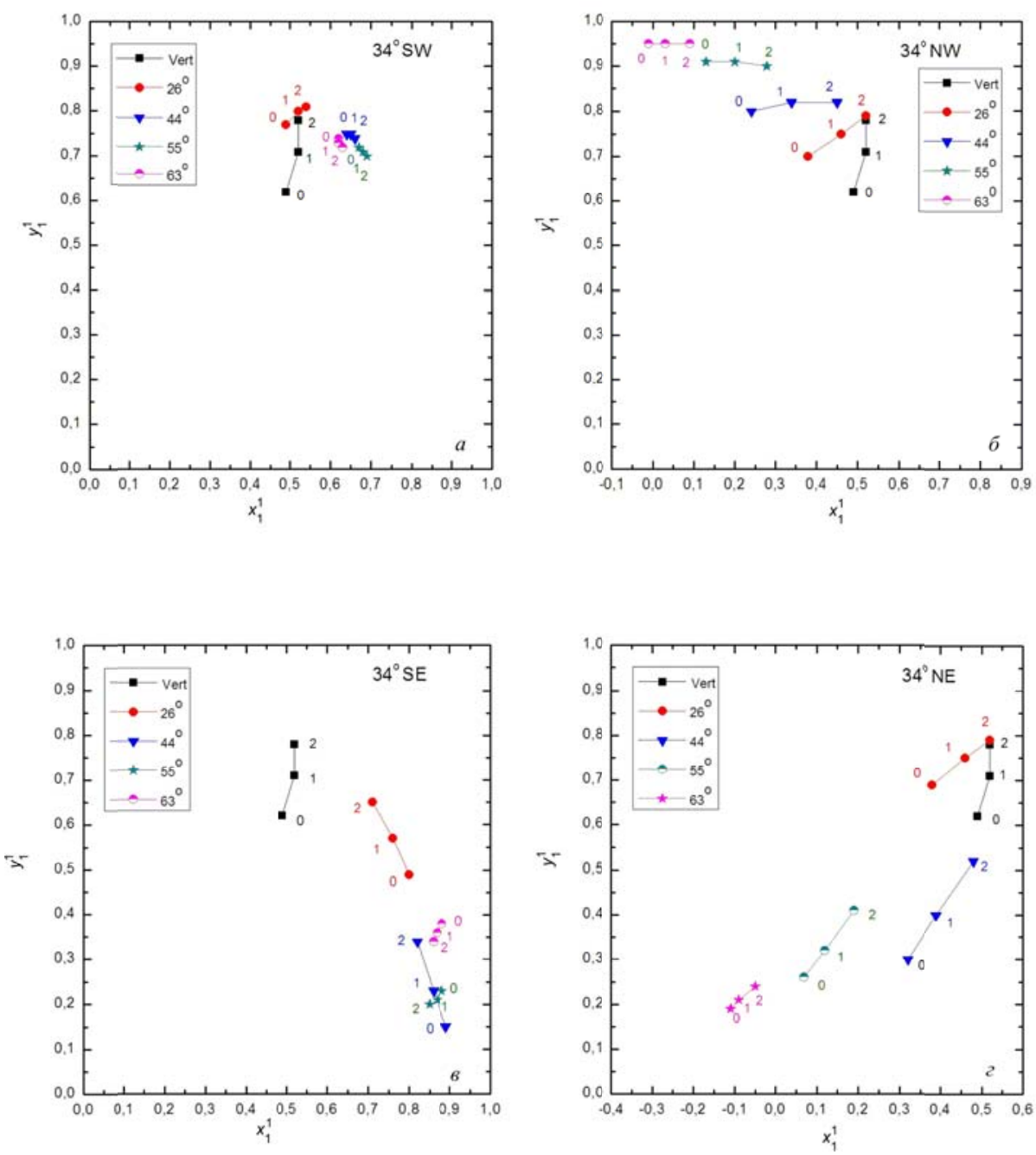

Figure 5. Receiving vector components of the first spherical harmonic for the $\mathrm{CR}$ muon telescope in Novosibirsk for SW (a), NW (b), SE (c), and NE (d) azimuth directions for $E_{0}=70 \mathrm{GeV}$, local time 
From a distance of $3 r_{0}\left(r_{0}\right.$ is the Earth radius), the contribution of harmonics above the second one to the geomagnetic field is less than $1 \%$; the step $h$ was then chosen as $h=h_{0}\left(r / 3 r_{0}\right)$. The trajectories were being determined until one of the following conditions had been fulfilled: $r \leq r_{0}, n=15000, r \geq 25 r_{0}$, where $n$ is the number of integration steps. Fulfillment of the first two conditions corresponded to forbidden trajectories. The distance $25 r_{0}$ being reached, the integration was stopped and finite particle trajectories were used to find the asymptotic latitude $\Phi(E, \theta, \varphi)$ and longitude $\Psi(E, \theta, \varphi)$.

\section{ENERGY SPECTRUM}

The results available from determination of energy spectra of the first and second spherical harmonics for $\mathrm{CR}$ distribution show a wide range of spectral variations. Their choice depends on problems to solve in studying CR distribution with these harmonics. To find components of the first harmonic, we selected a spectrum $f_{1}(E)$ as

$$
\begin{aligned}
& f_{1}(E) \sim E^{-\gamma} \text { if } E \leq E_{0}, \\
& f_{1}(E)=0 \text { if } E>E_{0} .
\end{aligned}
$$

Here $\gamma$ takes values $0,1,2$; and $E_{0}, 30,70,150 \mathrm{GeV}$.

To gauge the second spherical harmonic, we employed a spectrum $f_{2}(E)$ from [Krivoshapkin et al., 1989] where a screening mechanism for its generation is proposed. After approximation, it can be represented as follows:

$$
\begin{aligned}
& f_{2}(E) \sim\left(E / E_{0}\right) \text { if } E \leq E_{0}, \\
& f_{2}(E) \sim\left(E / E_{0}\right)^{-2} \text { if } E>E_{0},
\end{aligned}
$$

where $E_{0}=30,70,150 \mathrm{GeV}$.

\section{RECEIVING VECTORS}

Receiving vector components were calculated from the following equation [Chirkov et al., 1967]:

$$
Z_{n}^{m}=\frac{\int_{E_{\min }}^{\infty} \int_{0}^{2 \pi} \int_{0}^{\frac{\pi}{2}} W(E) f_{n}(E) N(\theta, \varphi) \sin (\theta) e^{i m \Psi(E, \theta, \varphi)} P_{n}^{m}(\sin \Phi(E, \theta, \varphi)) d E d \theta d \varphi}{\int_{E_{\min }}^{\infty} \int_{0}^{2 \pi} \int_{0}^{\frac{\pi}{2}} W(E) f_{n}(E) N(\theta, \varphi) \sin (\varphi) d E d \theta d \varphi},
$$

where $Z_{n}^{m}=x_{n}^{m}+i y_{n}^{m}$.

The product $e^{i m \Psi(E, \theta, \varphi)} P_{n}^{m}(\sin \Phi(E, \theta, \varphi))$ contains components

$x_{1}^{0}=\sin \Phi ; x_{1}^{1}=\cos \Phi \cos \Psi ; y_{1}^{1}=\cos \Phi \sin \Psi ;$

$x_{2}^{0}=\frac{3}{2} \sin ^{2} \Phi-\frac{1}{2} ; x_{2}^{1}=\sin 2 \Phi \cos \Psi ; y_{2}^{1}=\sin 2 \Phi \sin \Psi ;$ 


$$
x_{2}^{2}=\cos ^{2} \Phi \cos 2 \Psi ; y_{2}^{2}=\cos ^{2} \Phi \sin 2 \Psi .
$$

The component $x_{1}^{0}$ characterizes sensitivity of this detector to the contribution the first harmonic makes to the isotropic CR intensity component. The components $x_{1}^{1}$ and $y_{1}^{1}$ are respective radial and azimuth first harmonic components in geographic (UT) or intrinsic (LT) coordinate system. The LT components of receiving vectors are meant to analyze data for local time. For the global survey method, we have to use the UT components of receiving vectors. The modulus $\left|Z_{1}^{1}\right|=\sqrt{\left(x_{1}^{1}\right)^{2}+\left(y_{1}^{1}\right)^{2}}$ and the angle $Q_{1}^{1}=\operatorname{arctg}\left(y_{1}^{1} / x_{1}^{1}\right)$ describe the observable amplitude and phase variations in primary parameters of the first harmonic as function of latitude and longitude of an observation point. The amplitude varies over $1 /\left|Z_{1}^{1}\right|$; and the phase, over $Q_{1}^{1}$ degrees (i.e. with a positive value, they are shifted to a later time). For example, the receiving coefficients for the muon telescope at the CR station Novosibirsk (LT) in a vertical direction for the first harmonic (diurnal variation) are $x_{1}^{1}=0.56$ and $y_{1}^{1}=0.75$. In this case, the modulus of vector $\left|Z_{1}^{1}\right|=0.936$, the angle, $Q_{1}^{1}=53.3^{\circ}$, i.e. the observed amplitude is reduced 1.07 times with respect to the initial one; and the phase is shifted by $53.3^{\circ}$ (to a later time).

The component $x_{2}^{0}$ characterizes the contribution the second spherical harmonic makes to the isotropic CR intensity. The components $x_{2}^{1}$ and $y_{2}^{1}$ represent the antisymmetric diurnal variation resulting from the contribution of the second harmonic to the first one. Its phases are opposite in the Northern and Southern hemispheres. Accordingly, $x_{2}^{2}$ and $y_{2}^{2}$ are components of the second spherical harmonic of CR distribution. The moduli $\left|Z_{2}^{1}\right|=\sqrt{\left(x_{2}^{1}\right)^{2}+\left(y_{2}^{1}\right)^{2}},\left|Z_{2}^{2}\right|=\sqrt{\left(x_{2}^{2}\right)^{2}+\left(y_{2}^{2}\right)^{2}}$ and angles $Q_{2}^{1}=\operatorname{arctg}\left(y_{2}^{1} / x_{2}^{1}\right)$, $Q_{2}^{2}=\operatorname{arctg}\left(y_{2}^{2} / x_{2}^{2}\right)$ characterize their variations relative to the initial distribution, depending on coordinates of a CR station.

Figure 5, a-d illustrates receiving vector components for the first spherical harmonic of CR distribution for azimuth directions of $34^{\circ} \mathrm{SW}, 34^{\circ} \mathrm{NW}, 34^{\circ} \mathrm{SE}$, and $34^{\circ} \mathrm{NE}$ (LT) for $E_{0}=70 \mathrm{GeV}$ and $\gamma=0,1,2$. The results of calculation of the receiving vector components we obtained for the first and second spherical harmonics of CR distribution are listed in Tables 1-7 (Appendix A).

\section{CONCLUSION}

We have found receiving vector components for the muon telescope of the observation CR complex in Novosibirsk. Design features of the facility, its orientation, directional diagrams depending on zenith and azimuth angles, coupling coefficients for the complex of telescopes determined experimentally by the method of test detector were taken into account. The receiving characteristics of the complex we presented here are necessary to analyze modulation effects of CR intensity in a wide range of energies of primary particles. 


\section{REFERENCES}

Belov A.V., Eroshenko E.A., Ivanus' E.G., et al. Real time detection of cosmic ray anisotropy. Trudy 28 Vserossiiskoi konferentsii po kosmicheskim lucham [Proc. $28^{\text {th }}$ National Conference on Cosmic Rays]. Moscow, 2004. DKL2209 (CD-ROM) (in Russian).

Chirkov N.P., Altukhov A.M., Krymsky G.F., Krivo-shapkin P.A., Kuz'min A.I., Skripin G.V. Cosmic ray distribution and receiving vectors of detectors. III. Geomagnetizm i Aeronomiya. [Geomagnetism and Aeronomy]. 1967, vol. 7, no. 4, pp. 620-631 (in Russian).

Dvornikov V.M., Sdobnov V.E., Sergeev A.A., Sergeev A.V. Opredelenie koeffitsientov svyazi po variatsiyam zhestkostnogo spektra pervichnykh kosmicheskikh luchei [Detemining Correlation Coefficients from Variations of Rigidity Spectrum of Primary Cosmic Rays]: Preprint 14-89. Irkutsk, SibIZMIR Publ., 1989, 5 p. (in Russian).

Dorman L.I. Variatsii kosmicheskikh luchei [Cosmic Ray Variations]. Moscow, Gostekhizdat Publ., 1957. 285 p. (in Russian).

Dorman L.I., Smirnov V.S., Tyasto M.I. Kosmicheskie luchi v magnitnom pole Zemli [Cosmic Rays in the Earth's Magnetic Field]. Moscow, Nauka Publ., 1971, 309 p. (in Russian).

Grigoryev V.G., Krivoshapkin P.A., Krymsky G.F., Mamrukova V.P., Starodubtsev S.A., D’yachkovsky M.E. Receiving vectors of Yakutsk station complex of muon telescopes. Sbornik dokladov Vserossiiskoi konferentsii "Sovremennye problemy kosmicheskoi fiziki" [Proc. National Conference "Present Problems of Space Physics"]. Yakutsk Scientific Centre SB RAS Publ., 2007, pp. 99-102 (in Russian).

Grigoryev V.G., Chirkov N.P. Set'Stantsii kosmicheskikh luchei Sibiri i Dal'nego Vostoka [Network of Siberian and Far East Cosmic Ray Stations]: Preprint of Yakutsk Affiliated Branch SB AS USSR. Yakutsk, 1978, 32 p. (in Russian).

Kolmogorov A.N., Fomin S.V. Elementy teorii funktsii i funktsional'nogo analiza [Elements of the Theory of Functions and Functional Analysis]. Moscow, Nauka Publ., 1989, 624 p. (in Russian).

Krivoshapkin P.A., Krymsky G.F., Kuz'min A.I., Skripin G.V. Interplanetary field characteristics from half-daily cosmic ray variations. Geomagnetizm i Aeronomiya [Geomagnetism and Aeronomy]. 1969, vol. 9, no. 2, pp. $228-235$ (in Russian).

Krymsky G.F., Altukhov A.M., Kuz'min A.I., Krivo-shapkin P.A., Skripin G.V., Chirkov N.P. Cosmic ray distribution and receiving vectors of detectors. Geomagnetizm i Aeronomiya [Geomagnetism and Aeronomy]. 1966, vol. 6, no. 6, pp. 991-996 (in Russian).

Kuz'min A.I. Variatsii kosmicheskikh luchei vysokikh energii [Variations of High-Energy Cosmic Rays]. Moscow, Nauka. Publ., 1964, 159 p. (in Russian).

Kuz'min A.I. Variatsii kosmicheskikh luchei i solnechnaya aktivnost' [Cosmic Ray Variations and Solar Activity]. Moscow, Nauka Publ., 1968, 158 p. (in Russian).

Mori S. Theoretical calculation of the cosmic ray diurnal variation. 1. Nucleonic component. Nuovo Cimento. 1968a, vol. 58B, no. 10, pp. 1-57. DOI: 10.1007/BF02711778.

Mori S. Theoretical calculation of the cosmic ray solar diurnal variation. 2. Meson component. Nuovo Cimento. 1968b, vol. 58B, no. 10, pp. 58-70. DOI: 10.1007/BF02711779.

Murzin V.S. Fizika kosmicheskikh luchei [Physics of Cosmic Rays]. Moscow, Moscow State University Publ., 1970, 285 p. (in Russian).

Yanchukovsky A.L., Yanchukovsky V.L. Spectrograph of cosmic ray intensity variations for the world network of stations. Izvestiya AN SSSR. Ser. fizicheskaya. [Bulletin of the Academy of Sciences of the USSR. Physics]. 1982, vol. 46, no. 9, pp. 1746-1748 (in Russian).

Yanchukovsky V.L. Registratsiya napravlennoi intensivnosti kosmicheskikh luchei [Registration of Directed Intensity of Cosmic Rays]: Preprint no. 20. Novosibirsk, Institute of Geophysics and Geology Publ., 1986, 24 p. (in Russian). 
Yanchukovskiy V.L. Large proportional counters for cosmic ray detection. Geomagnetizm i Aeronomiya [Geomagnetism and Aeronomy]. 1994, vol. 34, no. 2, pp. 151-154 (in Russian).

Yanchukovskiy V.L., Filimonov G.Ya. Spectrograph of cosmic ray variations based on the effect of local electron generation. Astronomicheskii vestnik [Solar System Research]. 2000, vol. 34, no. 2, pp. 191-192 (in Russian).

Yanchukovskiy V.L. Cosmic ray telescope. Solnechno-zemnaya fizika [Solar-Terrestrial Physics]. Novosibirsk, SB RAS Publ., 2006, iss. 9, pp. 41-43 (in Russian).

Yanchukovskiy V.L. Estimation of energy diagrams of muon telescopes using the method of probe detector. Trudy Mezhdunarodnoi konferentsii "Vychislitel'nye i informatsionnye tekhnologii v nauke, tekhnike i obrazovanii" [Proc. Intern. Conference "Computational and Informatic Technologies in Science, Engineering and Education"]. Pavlodar State University Publ., 2006, pp. 359-362 (in Russian).

Yanchukovskiy V.L. Correlation coefficients for muons at different angles to zenit. Trudy Vserossiiskoi konferentsii "Sovremennye Problemy Kosmicheskoi Fiziki" [Proc. National Conference "Present Problems of Space Physics]. Yakutsk Scientific Centre SB RAS Publ., 2007, pp. 103-106 (in Russian).

Yanchukovskiy V.L. Multi-channel complex for cosmic ray observing. Solnechno-zemnaya fizika [SolarTerrestrial Physics]. Novosibirsk, SB RAS Publ., 2010, no. 16, pp. 107-109 (in Russian).

Yasue S., Mori S., Sakakibara S., Nagashima K. Coupling coefficients of cosmic ray daily variations for neutron monitor stations. Rep. of Cosmic Ray Research Laboratory. Nagoya University, 1982, no. 7, 6 p.

URL:ftp://nssdcftp.gsfc.nasa.gov/models/geomagnetic/igrf/fortran_code (accessed November 15, 2015)

\section{APPENDIX A}

Table 1. Receiving vector components of the first harmonic in a vertical direction

\begin{tabular}{|c|c|c|c|c|c|c|c|c|c|c|}
\hline \multicolumn{11}{|c|}{$\mathrm{LT}$} \\
\hline \multirow[b]{2}{*}{$\theta^{\circ}$} & \multirow[b]{2}{*}{$\gamma$} & \multicolumn{3}{|c|}{$E_{0}=30 \mathrm{GeV}$} & \multicolumn{3}{|c|}{$E_{0}=70 \mathrm{GeV}$} & \multicolumn{3}{|c|}{$E_{0}=150 \mathrm{GeV}$} \\
\hline & & $x_{1}^{0}$ & $x_{1}^{1}$ & $y_{1}^{1}$ & $x_{1}^{0}$ & $x_{1}^{1}$ & $y_{1}^{1}$ & $x_{1}^{0}$ & $x_{1}^{1}$ & $y_{1}^{1}$ \\
\hline \multirow{3}{*}{0} & 0 & 0.25 & 0.55 & 0.75 & 0.50 & 0.49 & 0.62 & 0.55 & 0.47 & 0.58 \\
\hline & 1 & 0.16 & 0.55 & 0.78 & 0.30 & 0.52 & 0.71 & 0.33 & 0.51 & 0.69 \\
\hline & 2 & 0.06 & 0.53 & 0.81 & 0.12 & 0.52 & 0.78 & 0.13 & 0.52 & 0.78 \\
\hline \multicolumn{11}{|c|}{ UT } \\
\hline & & \multicolumn{3}{|c|}{$E_{0}=30 \mathrm{GeV}$} & \multicolumn{3}{|c|}{$E_{0}=70 \mathrm{GeV}$} & \multicolumn{3}{|c|}{$E_{0}=150 \mathrm{GeV}$} \\
\hline$\theta^{\circ}$ & $\gamma$ & $x_{1}^{0}$ & $x_{1}^{1}$ & $y_{1}^{1}$ & $x_{1}^{0}$ & $x_{1}^{1}$ & $y_{1}^{1}$ & $x_{1}^{0}$ & $x_{1}^{1}$ & $y_{1}^{1}$ \\
\hline \multirow{3}{*}{0} & 0 & 0.25 & -0.68 & 0.64 & 0.50 & -0.56 & 0.56 & 0.55 & -0.52 & 0.54 \\
\hline & 1 & 0.16 & -0.71 & 0.64 & 0.30 & -0.64 & 0.60 & 0.33 & -0.63 & 0.59 \\
\hline & 2 & 0.06 & -0.74 & 0.63 & 0.12 & -0.71 & 0.62 & 0.13 & -0.71 & 0.61 \\
\hline
\end{tabular}

Table 2. Receiving vector components of the first harmonic in directions $\varphi=34^{\circ} \mathrm{NE}$ and $\theta=26,44,55$, and $63^{\circ}$

\begin{tabular}{|c|c|c|c|c|c|c|c|c|c|c|}
\hline \multicolumn{9}{|c|}{$E_{0}=30 \mathrm{GeV}$} & \multicolumn{3}{c|}{$E_{0}=70 \mathrm{GeV}$} & \multicolumn{3}{|c|}{$E_{0}=150 \mathrm{GeV}$} \\
\hline$\theta^{\circ}$ & $\gamma$ & $x_{1}^{0}$ & $x_{1}^{1}$ & $y_{1}^{1}$ & $x_{1}^{0}$ & $x_{1}^{1}$ & $y_{1}^{1}$ & $x_{1}^{0}$ & $x_{1}^{1}$ & $y_{1}^{1}$ \\
\hline 26 & 0 & 0.22 & 0.50 & 0.80 & 0.49 & 0.38 & 0.69 & 0.55 & 0.35 & 0.64 \\
& 1 & 0.15 & 0.53 & 0.81 & 0.31 & 0.46 & 0.75 & 0.34 & 0.44 & 0.73 \\
& 2 & 0.09 & 0.55 & 0.81 & 0.16 & 0.52 & 0.79 & 0.17 & 0.52 & 0.78 \\
& & & & & & & & &
\end{tabular}




\begin{tabular}{|c|c|c|c|c|c|c|c|c|c|c|}
\hline \multirow[t]{3}{*}{44} & 0 & 0.64 & 0.44 & 0.51 & 0.82 & 0.32 & 0.30 & 0.84 & 0.31 & 0.31 \\
\hline & 1 & 0.54 & 0.48 & 0.57 & 0.70 & 0.39 & 0.40 & 0.71 & 0.38 & 0.40 \\
\hline & 2 & 0.43 & 0.53 & 0.62 & 0.54 & 0.48 & 0.52 & 0.55 & 0.47 & 0.52 \\
\hline \multirow[t]{3}{*}{55} & 0 & 0.75 & 0.25 & 0.55 & 0.92 & 0.07 & 0.26 & 0.92 & 0.05 & 0.29 \\
\hline & 1 & 0.70 & 0.29 & 0.57 & 0.87 & 0.12 & 0.32 & 0.88 & 0.11 & 0.33 \\
\hline & 2 & 0.64 & 0.33 & 0.60 & 0.79 & 0.19 & 0.41 & 0.80 & 0.18 & 0.41 \\
\hline \multirow{3}{*}{63} & 0 & 0.78 & 0.15 & 0.57 & 0.95 & -0.11 & 0.19 & 0.93 & -0.13 & 0.28 \\
\hline & 1 & 0.77 & 0.16 & 0.58 & 0.94 & -0.09 & 0.21 & 0.93 & -0.11 & 0.27 \\
\hline & 2 & 0.75 & 0.18 & 0.60 & 0.92 & -0.05 & 0.21 & 0.92 & -0.07 & 0.27 \\
\hline \multicolumn{11}{|c|}{ UT } \\
\hline \multicolumn{5}{|c|}{$E_{0}=30 \mathrm{GeV}$} & \multicolumn{3}{|c|}{$E_{0}=70 \mathrm{GeV}$} & \multicolumn{3}{|c|}{$E_{0}=150 \mathrm{GeV}$} \\
\hline$\theta^{\circ}$ & $\gamma$ & $x_{1}^{0}$ & $x_{1}^{1}$ & $y_{1}^{1}$ & $x_{1}^{0}$ & $x_{1}^{1}$ & $y_{1}^{1}$ & $x_{1}^{0}$ & $x_{1}^{1}$ & $y_{1}^{1}$ \\
\hline \multirow{3}{*}{26} & 0 & 0.22 & -0.74 & 0.59 & 0.49 & -0.64 & 0.46 & 0.55 & -0.59 & 0.43 \\
\hline & 1 & 0.15 & -0.74 & 0.62 & 0.31 & -0.69 & 0.54 & 0.34 & -0.67 & 0.53 \\
\hline & 2 & 0.09 & -0.73 & 0.65 & 0.16 & -0.72 & 0.61 & 0.17 & -0.71 & 0.61 \\
\hline \multirow{3}{*}{44} & 0 & 0.64 & -0.45 & 0.49 & 0.82 & -0.11 & 0.34 & 0.84 & -0.02 & 0.32 \\
\hline & 1 & 0.54 & -0.50 & 0.55 & 0.70 & -0.27 & 0.43 & 0.71 & -0.22 & 0.41 \\
\hline & 2 & 0.43 & -0.55 & 0.60 & 0.54 & -0.43 & 0.53 & 0.55 & -0.41 & 0.53 \\
\hline \multirow{3}{*}{55} & 0 & 0.75 & -0.51 & 0.32 & 0.92 & -0.10 & 0.12 & 0.92 & 0.02 & 0.11 \\
\hline & 1 & 0.70 & -0.53 & 0.35 & 0.87 & -0.21 & 0.17 & 0.88 & -0.14 & 0.16 \\
\hline & 2 & 0.64 & -0.56 & 0.40 & 0.79 & -0.33 & 0.25 & 0.80 & -0.29 & 0.24 \\
\hline \multirow{3}{*}{63} & 0 & 0.78 & -0.55 & 0.21 & 0.95 & 0.03 & 0.14 & 0.93 & 0.18 & 0.17 \\
\hline & 1 & 0.77 & -0.56 & 0.23 & 0.94 & -0.04 & 0.13 & 0.93 & 0.09 & 0.16 \\
\hline & 2 & 0.75 & -0.57 & 0.25 & 0.92 & -0.13 & 0.13 & 0.92 & -0.03 & 0.15 \\
\hline
\end{tabular}

Table 3. Receiving vector components of the first harmonic in directions $\varphi=34^{\circ} \mathrm{NW}$ and $\theta=26,44,55$, and $63^{\circ}$

\begin{tabular}{|l|l|l|l|l|l|l|l|l|l|l|}
\hline \multicolumn{9}{|c|}{$E_{0}=30 \mathrm{GeV}$} & \multicolumn{3}{|c|}{$E_{0}=70 \mathrm{GeV}$} & \multicolumn{3}{c|}{$E_{0}=150 \mathrm{GeV}$} \\
\hline$\theta^{\circ}$ & $\gamma$ & $x_{1}^{0}$ & $x_{1}^{1}$ & $y_{1}^{1}$ & $x_{1}^{0}$ & $x_{1}^{1}$ & $y_{1}^{1}$ & $x_{1}^{0}$ & $x_{1}^{1}$ & $y_{1}^{1}$ \\
\hline 26 & 0 & 0.21 & 0.50 & 0.81 & 0.48 & 0.38 & 0.70 & 0.54 & 0.35 & 0.65 \\
& 1 & 0.14 & 0.53 & 0.81 & 0.30 & 0.46 & 0.75 & 0.33 & 0.45 & 0.73 \\
& 2 & 0.08 & 0.55 & 0.81 & 0.15 & 0.52 & 0.79 & 0.16 & 0.52 & 0.78 \\
\hline 44 & 0 & 0.09 & 0.44 & 0.87 & 0.41 & 0.24 & 0.80 & 0.48 & 0.19 & 0.75 \\
& 1 & 0.06 & 0.48 & 0.85 & 0.27 & 0.34 & 0.82 & 0.31 & 0.32 & 0.80 \\
& 2 & 0.04 & 0.52 & 0.83 & 0.14 & 0.45 & 0.82 & 0.16 & 0.44 & 0.82 \\
\hline 55 & 0 & -0.07 & 0.37 & 0.91 & 0.26 & 0.13 & 0.91 & 0.36 & 0.07 & 0.87 \\
& 1 & -0.08 & 0.39 & 0.90 & 0.17 & 0.20 & 0.91 & 0.23 & 0.16 & 0.89 \\
& 2 & -0.09 & 0.42 & 0.88 & 0.09 & 0.28 & 0.90 & 0.12 & 0.26 & 0.90 \\
\hline 63 & 0 & -0.20 & 0.32 & 0.92 & 0.22 & -0.01 & 0.95 & 0.35 & -0.09 & 0.90 \\
& 1 & -0.20 & 0.33 & 0.91 & 0.17 & 0.03 & 0.95 & 0.27 & -0.04 & 0.91 \\
& 2 & -0.20 & 0.35 & 0.91 & 0.10 & 0.09 & 0.95 & 0.18 & 0.03 & 0.93 \\
\hline
\end{tabular}




\begin{tabular}{|c|c|c|c|c|c|c|c|c|c|c|}
\hline \multicolumn{11}{|c|}{ UT } \\
\hline \multicolumn{5}{|c|}{$E_{0}=30 \mathrm{GeV}$} & \multicolumn{3}{|c|}{$E_{0}=70 \mathrm{GeV}$} & \multicolumn{3}{|c|}{$E_{0}=150 \mathrm{GeV}$} \\
\hline$\theta^{\circ}$ & $\gamma$ & $x_{1}^{0}$ & $x_{1}^{1}$ & $y_{1}^{1}$ & $x_{1}^{0}$ & $x_{1}^{1}$ & $y_{1}^{1}$ & $x_{1}^{0}$ & $x_{1}^{1}$ & $y_{1}^{1}$ \\
\hline \multirow[t]{3}{*}{26} & 0 & 0.21 & -0.74 & 0.59 & 0.48 & -0.64 & 0.46 & 0.54 & -0.60 & 0.43 \\
\hline & 1 & 0.14 & -0.74 & 0.62 & 0.30 & -0.68 & 0.55 & 0.33 & -0.68 & 0.53 \\
\hline & 2 & 0.08 & -0.74 & 0.64 & 0.15 & -0.72 & 0.61 & 0.16 & -0.72 & 0.61 \\
\hline \multirow[t]{3}{*}{44} & 0 & 0.09 & -0.81 & 0.54 & 0.41 & -0.76 & 0.34 & 0.48 & -0.72 & 0.28 \\
\hline & 1 & 0.06 & -0.78 & 0.58 & 0.27 & -0.77 & 0.44 & 0.31 & -0.76 & 0.41 \\
\hline & 2 & 0.04 & -0.76 & 0.62 & 0.14 & -0.76 & 0.54 & 0.16 & -0.76 & 0.53 \\
\hline \multirow[t]{3}{*}{55} & 0 & -0.07 & -0.86 & 0.48 & 0.26 & -0.88 & 0.24 & 0.36 & -0.85 & 0.18 \\
\hline & 1 & -0.08 & -0.85 & 0.50 & 0.17 & -0.88 & 0.31 & 0.23 & -0.86 & 0.27 \\
\hline & 2 & -0.09 & -0.83 & 0.53 & 0.09 & -0.86 & 0.39 & 0.12 & -0.86 & 0.37 \\
\hline \multirow[t]{3}{*}{63} & 0 & -0.20 & -0.87 & 0.43 & 0.22 & -0.94 & 0.11 & 0.35 & -0.90 & 0.02 \\
\hline & 1 & -0.20 & -0.87 & 0.44 & 0.17 & -0.94 & 0.15 & 0.27 & -0.91 & 0.07 \\
\hline & 2 & -0.20 & -0.86 & 0.46 & 0.10 & -0.93 & 0.20 & 0.18 & -0.92 & 0.14 \\
\hline
\end{tabular}

Table 4. Receiving vector components of the first harmonic in directions $\varphi=34^{\circ} \mathrm{SE}$ and $\theta=26,44,55$, and $63^{\circ}$

\begin{tabular}{|c|c|c|c|c|c|c|c|c|c|c|}
\hline \multicolumn{11}{|c|}{ LT } \\
\hline \multicolumn{5}{|c|}{$E_{0}=30 \mathrm{GeV}$} & \multicolumn{3}{|c|}{$E_{0}=70 \mathrm{GeV}$} & \multicolumn{3}{|c|}{$E_{0}=150 \mathrm{GeV}$} \\
\hline$\theta^{\circ}$ & $\gamma$ & $x_{1}^{0}$ & $x_{1}^{1}$ & $y_{1}^{1}$ & $x_{1}^{0}$ & $x_{1}^{1}$ & $y_{1}^{1}$ & $x_{1}^{0}$ & $x_{1}^{1}$ & $y_{1}^{1}$ \\
\hline \multirow[t]{3}{*}{26} & 0 & 0.19 & 0.77 & 0.58 & 0.27 & 0.80 & 0.49 & 0.29 & 0.80 & 0.47 \\
\hline & 1 & 0.15 & 0.74 & 0.62 & 0.20 & 0.76 & 0.57 & 0.21 & 0.77 & 0.55 \\
\hline & 2 & 0.10 & 0.69 & 0.68 & 0.13 & 0.71 & 0.65 & 0.13 & 0.71 & 0.64 \\
\hline \multirow[t]{3}{*}{44} & 0 & 0.42 & 0.84 & 0.26 & 0.38 & 0.89 & 0.15 & 0.36 & 0.90 & 0.14 \\
\hline & 1 & 0.40 & 0.82 & 0.33 & 0.38 & 0.86 & 0.23 & 0.38 & 0.86 & 0.22 \\
\hline & 2 & 0.37 & 0.79 & 0.40 & 0.37 & 0.82 & 0.34 & 0.36 & 0.82 & 0.33 \\
\hline \multirow[t]{3}{*}{55} & 0 & 0.54 & 0.82 & 0.13 & 0.37 & 0.88 & 0.23 & 0.33 & 0.89 & 0.25 \\
\hline & 1 & 0.54 & 0.82 & 0.15 & 0.42 & 0.87 & 0.21 & 0.39 & 0.87 & 0.22 \\
\hline & 2 & 0.54 & 0.81 & 0.17 & 0.46 & 0.85 & 0.20 & 0.44 & 0.85 & 0.21 \\
\hline \multirow[t]{3}{*}{63} & 0 & 0.55 & 0.80 & 0.21 & 0.25 & 0.88 & 0.38 & 0.17 & 0.89 & 0.39 \\
\hline & 1 & 0.55 & 0.80 & 0.20 & 0.28 & 0.87 & 0.36 & 0.22 & 0.88 & 0.38 \\
\hline & 2 & 0.56 & 0.80 & 0.19 & 0.33 & 0.86 & 0.34 & 0.28 & 0.87 & 0.35 \\
\hline \multicolumn{11}{|c|}{ UT } \\
\hline \multicolumn{5}{|c|}{$E_{0}=30 \mathrm{GeV}$} & \multicolumn{3}{|c|}{$E_{0}=70 \mathrm{GeV}$} & \multicolumn{3}{|c|}{$E_{0}=150 \mathrm{GeV}$} \\
\hline$\theta^{\circ}$ & $\gamma$ & $x_{1}^{0}$ & $x_{1}^{1}$ & $y_{1}^{1}$ & $x_{1}^{0}$ & $x_{1}^{1}$ & $y_{1}^{1}$ & $x_{1}^{0}$ & $x_{1}^{1}$ & $y_{1}^{1}$ \\
\hline \multirow[t]{3}{*}{26} & 0 & 0.19 & -0.48 & 0.84 & 0.27 & -0.39 & 0.85 & 0.29 & -0.37 & 0.86 \\
\hline & 1 & 0.15 & -0.53 & 0.81 & 0.20 & -0.47 & 0.83 & 0.21 & -0.46 & 0.83 \\
\hline & 2 & 0.10 & -0.59 & 0.77 & 0.13 & -0.56 & 0.78 & 0.13 & -0.55 & 0.78 \\
\hline
\end{tabular}




\begin{tabular}{|c|c|c|c|c|c|c|c|c|c|c|}
\hline 44 & 0 & 0.42 & -0.15 & 0.86 & 0.38 & 0.03 & 0.89 & 0.36 & 0.06 & 0.90 \\
& 1 & 0.40 & -0.22 & 0.85 & 0.38 & -0.08 & 0.88 & 0.38 & -0.06 & 0.88 \\
& 2 & 0.37 & -0.30 & 0.84 & 0.37 & -0.21 & 0.85 & 0.36 & -0.21 & 0.85 \\
\hline 55 & 0 & 0.54 & 0.13 & 0.81 & 0.37 & 0.31 & 0.85 & 0.33 & 0.34 & 0.86 \\
& 1 & 0.54 & 0.09 & 0.81 & 0.42 & 0.26 & 0.84 & 0.39 & 0.28 & 0.85 \\
& 2 & 0.54 & 0.04 & 0.81 & 0.46 & 0.18 & 0.83 & 0.44 & 0.19 & 0.83 \\
\hline 63 & 0 & 0.55 & 0.29 & 0.77 & 0.25 & 0.48 & 0.83 & 0.17 & 0.50 & 0.84 \\
& 1 & 0.55 & 0.28 & 0.77 & 0.28 & 0.46 & 0.82 & 0.22 & 0.48 & 0.83 \\
& 2 & 0.56 & 0.26 & 0.77 & 0.33 & 0.44 & 0.81 & 0.28 & 0.45 & 0.82 \\
\hline
\end{tabular}

Table 5. Receiving vector components of the first harmonic in directions $\varphi=34^{\circ} \mathrm{SW}$ and $\theta=26,44,55$, and $63^{\circ}$

\begin{tabular}{|c|c|c|c|c|c|c|c|c|c|c|}
\hline \multicolumn{11}{|c|}{ LT } \\
\hline \multicolumn{5}{|c|}{$E_{0}=30 \mathrm{GeV}$} & \multicolumn{3}{|c|}{$E_{0}=70 \mathrm{GeV}$} & \multicolumn{3}{|c|}{$E_{0}=150 \mathrm{GeV}$} \\
\hline$\theta^{\circ}$ & $\gamma$ & $x_{1}^{0}$ & $x_{1}^{1}$ & $y_{1}^{1}$ & $x_{1}^{0}$ & $x_{1}^{1}$ & $y_{1}^{1}$ & $x_{1}^{0}$ & $x_{1}^{1}$ & $y_{1}^{1}$ \\
\hline \multirow[t]{3}{*}{26} & 0 & 0.06 & 0.55 & 0.81 & 0.28 & 0.49 & 0.77 & 0.34 & 0.47 & 0.75 \\
\hline & 1 & 0.03 & 0.56 & 0.82 & 0.15 & 0.52 & 0.80 & 0.18 & 0.51 & 0.79 \\
\hline & 2 & 0.00 & 0.55 & 0.82 & 0.05 & 0.54 & 0.81 & 0.06 & 0.54 & 0.81 \\
\hline \multirow[t]{3}{*}{44} & 0 & -0.07 & 0.67 & 0.74 & 0.04 & 0.64 & 0.75 & 0.08 & 0.63 & 0.75 \\
\hline & 1 & -0.06 & 0.67 & 0.73 & 0.00 & 0.65 & 0.75 & 0.02 & 0.65 & 0.75 \\
\hline & 2 & -0.04 & 0.67 & 0.74 & -0.02 & 0.66 & 0.74 & -0.02 & 0.66 & 0.74 \\
\hline \multirow[t]{3}{*}{55} & 0 & -0.18 & 0.71 & 0.68 & -0.13 & 0.67 & 0.72 & -0.09 & 0.66 & 0.73 \\
\hline & 1 & -0.17 & 0.71 & 0.67 & -0.14 & 0.68 & 0.71 & -0.12 & 0.67 & 0.72 \\
\hline & 2 & -0.15 & 0.72 & 0.67 & -0.15 & 0.69 & 0.70 & -0.14 & 0.69 & 0.70 \\
\hline \multirow[t]{3}{*}{63} & 0 & -0.28 & 0.69 & 0.66 & -0.26 & 0.62 & 0.74 & -0.21 & 0.61 & 0.76 \\
\hline & 1 & -0.28 & 0.70 & 0.66 & -0.27 & 0.62 & 0.73 & -0.23 & 0.62 & 0.74 \\
\hline & 2 & -0.27 & 0.70 & 0.65 & -0.27 & 0.63 & 0.72 & -0.25 & 0.63 & 0.73 \\
\hline \multicolumn{11}{|c|}{ UT } \\
\hline \multicolumn{5}{|c|}{$E_{0}=30 \mathrm{GeV}$} & \multicolumn{3}{|c|}{$E_{0}=70 \mathrm{GeV}$} & \multicolumn{3}{|c|}{$E_{0}=150 \mathrm{GeV}$} \\
\hline$\theta^{\circ}$ & $\gamma$ & $x_{1}^{0}$ & $x_{1}^{1}$ & $y_{1}^{1}$ & $x_{1}^{0}$ & $x_{1}^{1}$ & $y_{1}^{1}$ & $x_{1}^{0}$ & $x_{1}^{1}$ & $y_{1}^{1}$ \\
\hline \multirow[t]{3}{*}{26} & 0 & 0.06 & -0.74 & 0.65 & 0.28 & -0.71 & 0.58 & 0.34 & -0.69 & 0.56 \\
\hline & 1 & 0.03 & -0.74 & 0.65 & 0.15 & -0.73 & 0.61 & 0.18 & -0.72 & 0.61 \\
\hline & 2 & 0.00 & -0.75 & 0.65 & 0.05 & -0.74 & 0.63 & 0.06 & -0.74 & 0.63 \\
\hline \multirow[t]{3}{*}{44} & 0 & -0.07 & -0.65 & 0.75 & 0.04 & -0.67 & 0.73 & 0.08 & -0.67 & 0.72 \\
\hline & 1 & -0.06 & -0.65 & 0.75 & 0.00 & -0.66 & 0.74 & 0.02 & -0.66 & 0.73 \\
\hline & 2 & -0.04 & -0.65 & 0.75 & -0.02 & -0.66 & 0.74 & -0.02 & -0.66 & 0.74 \\
\hline \multirow[t]{3}{*}{55} & 0 & -0.18 & -0.59 & 0.78 & -0.13 & -0.64 & 0.75 & -0.09 & -0.65 & 0.75 \\
\hline & 1 & -0.17 & -0.58 & 0.79 & -0.14 & -0.62 & 0.76 & -0.12 & -0.63 & 0.76 \\
\hline & 2 & -0.15 & -0.58 & 0.80 & -0.15 & -0.61 & 0.77 & -0.14 & -0.61 & 0.77 \\
\hline
\end{tabular}




\begin{tabular}{|c|c|c|c|c|c|c|c|c|c|c|}
\hline 63 & 0 & -0.28 & -0.57 & 0.77 & -0.26 & -0.66 & 0.70 & -0.21 & -0.68 & 0.70 \\
& 1 & -0.28 & -0.57 & 0.77 & -0.27 & -0.65 & 0.71 & -0.23 & -0.66 & 0.70 \\
& 2 & -0.27 & -0.56 & 0.78 & -0.27 & -0.63 & 0.72 & -0.25 & -0.65 & 0.71 \\
\hline
\end{tabular}

Table 6. Receiving vector components (UT) of the second harmonics

\begin{tabular}{|c|c|c|c|c|c|c|}
\hline$\theta^{\circ}$ & $E_{0}, \mathrm{GeV}$ & $x_{2}^{0}$ & $x_{2}^{1}$ & $y_{2}^{1}$ & $x_{2}^{2}$ & $y_{2}^{2}$ \\
\hline \multicolumn{7}{|c|}{ Vertical } \\
\hline \multirow{3}{*}{0} & 30 & -0.02 & -0.51 & 0.53 & 0.02 & -0.67 \\
\hline & 70 & 0.29 & -0.53 & 0.64 & -0.04 & -0.45 \\
\hline & 150 & 0.41 & -0.46 & 0.65 & -0.06 & -0.36 \\
\hline \multicolumn{7}{|c|}{ Direction $\varphi=34^{\circ} \mathrm{SW}$} \\
\hline \multirow{3}{*}{26} & 30 & -0.27 & -0.16 & 0.64 & -0.67 & -0.42 \\
\hline & 70 & -0.23 & -0.11 & 0.71 & -0.73 & -0.26 \\
\hline & 150 & -0.22 & -0.08 & 0.73 & -0.74 & -0.19 \\
\hline \multirow{3}{*}{44} & 30 & 0.08 & 0.16 & 0.88 & -0.45 & 0.17 \\
\hline & 70 & -0.02 & 0.32 & 0.80 & -0.41 & 0.44 \\
\hline & 150 & -0.09 & 0.34 & 0.74 & -0.39 & 0.53 \\
\hline \multirow{3}{*}{55} & 30 & 0.24 & 0.44 & 0.78 & -0.16 & 0.40 \\
\hline & 70 & 0.02 & 0.56 & 0.66 & -0.04 & 0.61 \\
\hline & 150 & -0.10 & 0.53 & 0.57 & 0.01 & 0.71 \\
\hline \multirow{3}{*}{63} & 30 & 0.05 & 0.63 & 0.55 & 0.14 & 0.59 \\
\hline & 70 & -0.15 & 0.62 & 0.45 & 0.24 & 0.71 \\
\hline & 150 & -0.28 & 0.50 & 0.35 & 0.29 & 0.79 \\
\hline \multicolumn{7}{|c|}{ Direction $\varphi=34^{\circ} \mathrm{NW}$} \\
\hline \multirow{3}{*}{26} & 30 & -0.07 & -0.56 & 0.37 & 0.22 & -0.65 \\
\hline & 70 & 0.29 & -0.66 & 0.42 & 0.16 & -0.42 \\
\hline & 150 & 0.44 & -0.59 & 0.41 & 0.12 & -0.32 \\
\hline \multirow{3}{*}{44} & 30 & -0.20 & -0.52 & 0.16 & 0.46 & -0.59 \\
\hline & 70 & 0.14 & -0.76 & 0.16 & 0.42 & -0.32 \\
\hline & 150 & 0.33 & -0.74 & 0.10 & 0.31 & -0.21 \\
\hline \multirow{3}{*}{55} & 30 & -0.34 & -0.32 & 0.02 & 0.67 & -0.51 \\
\hline & 70 & -0.13 & -0.69 & 0.03 & 0.67 & -0.23 \\
\hline & 150 & 0.02 & -0.77 & -0.05 & 0.55 & -0.10 \\
\hline \multirow{3}{*}{63} & 30 & -0.32 & -0.38 & -0.05 & 0.78 & -0.21 \\
\hline & 70 & -0.21 & -0.66 & -0.07 & 0.77 & 0.00 \\
\hline & 150 & -0.01 & -0.79 & -0.19 & 0.60 & 0.15 \\
\hline \multicolumn{7}{|c|}{ Direction $\varphi=34^{\circ} \mathrm{SE}$} \\
\hline \multirow{3}{*}{26} & 30 & -0.37 & -0.19 & 0.47 & -0.58 & -0.66 \\
\hline & 70 & -0.30 & -0.20 & 0.58 & -0.64 & -0.55 \\
\hline & 150 & -0.26 & -0.19 & 0.63 & -0.65 & -0.50 \\
\hline
\end{tabular}




\begin{tabular}{|c|c|c|c|c|c|c|}
\hline \multirow{3}{*}{44} & 30 & -0.25 & 0.01 & 0.70 & -0.76 & 0.04 \\
\hline & 70 & -0.31 & 0.08 & 0.62 & -0.80 & 0.22 \\
\hline & 150 & -0.33 & 0.09 & 0.58 & -0.80 & 0.28 \\
\hline \multirow{3}{*}{55} & 30 & -0.22 & 0.21 & 0.68 & -0.61 & 0.48 \\
\hline & 70 & -0.35 & 0.20 & 0.50 & -0.61 & 0.63 \\
\hline & 150 & -0.39 & 0.17 & 0.40 & -0.61 & 0.68 \\
\hline \multirow{3}{*}{63} & 30 & -0.36 & 0.22 & 0.40 & -0.45 & 0.77 \\
\hline & 70 & -0.44 & 0.15 & 0.24 & -0.45 & 0.84 \\
\hline & 150 & -0.47 & 0.07 & 0.10 & -0.45 & 0.85 \\
\hline \multicolumn{7}{|c|}{ Direction $\varphi=34^{\circ} \mathrm{NE}$} \\
\hline \multirow{3}{*}{26} & 30 & -0.05 & -0.57 & 0.37 & 0.21 & -0.64 \\
\hline & 70 & 0.31 & -0.65 & 0.42 & 0.16 & -0.40 \\
\hline & 150 & 0.46 & -0.58 & 0.41 & 0.11 & -0.31 \\
\hline \multirow{3}{*}{44} & 30 & 0.59 & -0.19 & 0.52 & -0.02 & -0.19 \\
\hline & 70 & 0.71 & 0.24 & 0.45 & 0.02 & 0.01 \\
\hline & 150 & 0.64 & 0.43 & 0.42 & 0.08 & 0.08 \\
\hline \multirow{3}{*}{55} & 30 & 0.74 & -0.27 & 0.23 & 0.09 & -0.12 \\
\hline & 70 & 0.83 & 0.22 & 0.14 & 0.09 & -0.01 \\
\hline & 150 & 0.72 & 0.16 & 0.13 & 0.17 & 0.02 \\
\hline \multirow{3}{*}{63} & 30 & 0.78 & 0.04 & 0.25 & 0.09 & 0.03 \\
\hline & 70 & 0.77 & 0.41 & 0.32 & 0.08 & 0.09 \\
\hline & 150 & 0.59 & 0.65 & 0.32 & 0.20 & 0.16 \\
\hline
\end{tabular}

Table 7. Receiving vector components (LT) of the second harmonics

\begin{tabular}{|c|c|c|c|c|c|c|}
\hline$\theta^{\circ}$ & $E_{0}$, ГэВ & $x_{2}^{0}$ & $x_{2}^{1}$ & $y_{2}^{1}$ & $x_{2}^{2}$ & $y_{2}^{2}$ \\
\hline \multicolumn{6}{|c|}{ Vertical } \\
\hline \multirow{2}{*}{0} & 30 & -0.02 & 0.46 & 0.57 & -0.18 & 0.65 \\
& 70 & 0.29 & 0.57 & 0.61 & -0.07 & 0.45 \\
& 150 & 0.41 & 0.59 & 0.54 & -0.03 & 0.36 \\
\hline \multicolumn{6}{|c|}{ Direction $\varphi=34^{\circ} \mathrm{SW}$} \\
\hline \multirow{2}{*}{26} & 30 & -0.27 & 0.62 & 0.24 & 0.55 & 0.57 \\
& 70 & -0.23 & 0.69 & 0.20 & 0.65 & 0.43 \\
& 150 & -0.22 & 0.72 & 0.17 & 0.68 & 0.38 \\
\hline \multirow{5}{*}{54} & 30 & 0.08 & 0.89 & 0.22 & 0.48 & 0.30 \\
& 70 & -0.02 & 0.84 & 0.28 & 0.50 & 0.40 \\
& 150 & -0.09 & 0.78 & 0.29 & 0.50 & 0.47 \\
\hline \multirow{2}{*}{55} & 30 & 0.24 & 0.83 & 0.40 & 0.25 & 0.40 \\
& 70 & 0.02 & 0.73 & 0.49 & 0.19 & 0.60 \\
& 150 & -0.10 & 0.63 & 0.47 & 0.16 & 0.69 \\
\hline
\end{tabular}




\begin{tabular}{|c|c|c|c|c|c|c|}
\hline 63 & $\begin{array}{c}30 \\
70 \\
150\end{array}$ & $\begin{array}{c}0.05 \\
-0.15 \\
-0.28\end{array}$ & $\begin{array}{l}0.62 \\
0.53 \\
0.41\end{array}$ & $\begin{array}{l}0.56 \\
0.56 \\
0.45\end{array}$ & $\begin{array}{c}0.01 \\
-0.06 \\
-0.09\end{array}$ & $\begin{array}{l}0.61 \\
0.75 \\
0.84\end{array}$ \\
\hline \multicolumn{7}{|c|}{ Direction $\varphi=34^{\circ} \mathrm{NW}$} \\
\hline 26 & $\begin{array}{c}30 \\
70 \\
150\end{array}$ & $\begin{array}{c}-0.07 \\
0.29 \\
0.44\end{array}$ & $\begin{array}{l}0.30 \\
0.34 \\
0.33\end{array}$ & $\begin{array}{l}0.60 \\
0.70 \\
0.63\end{array}$ & $\begin{array}{l}-0.37 \\
-0.26 \\
-0.19\end{array}$ & $\begin{array}{l}0.58 \\
0.36 \\
0.28\end{array}$ \\
\hline 44 & $\begin{array}{c}30 \\
70 \\
150\end{array}$ & $\begin{array}{c}-0.20 \\
0.14 \\
0.33\end{array}$ & $\begin{array}{l}0.10 \\
0.07 \\
0.01\end{array}$ & $\begin{array}{l}0.53 \\
0.77 \\
0.74\end{array}$ & $\begin{array}{r}-0.59 \\
-0.48 \\
-0.38\end{array}$ & $\begin{array}{l}0.46 \\
0.21 \\
0.13\end{array}$ \\
\hline 55 & $\begin{array}{c}30 \\
70 \\
150\end{array}$ & $\begin{array}{c}-0.34 \\
-0.13 \\
0.02\end{array}$ & $\begin{array}{l}-0.02 \\
-0.05 \\
-0.14\end{array}$ & $\begin{array}{l}0.32 \\
0.68 \\
0.76\end{array}$ & $\begin{array}{l}-0.77 \\
-0.70 \\
-0.56\end{array}$ & $\begin{array}{r}0.33 \\
0.06 \\
-0.04\end{array}$ \\
\hline 63 & $\begin{array}{c}30 \\
70 \\
150\end{array}$ & $\begin{array}{l}-0.32 \\
-0.21 \\
-0.01\end{array}$ & $\begin{array}{l}-0.10 \\
-0.15 \\
-0.29\end{array}$ & $\begin{array}{l}0.37 \\
0.64 \\
0.76\end{array}$ & $\begin{array}{l}-0.81 \\
-0.74 \\
-0.54\end{array}$ & $\begin{array}{r}0.02 \\
-0.19 \\
-0.29\end{array}$ \\
\hline \multicolumn{7}{|c|}{ Direction $\varphi=34^{\circ} \mathrm{SE}$} \\
\hline 26 & $\begin{array}{c}30 \\
70 \\
150\end{array}$ & $\begin{array}{l}-0.37 \\
-0.30 \\
-0.26\end{array}$ & $\begin{array}{l}0.44 \\
0.56 \\
0.61\end{array}$ & $\begin{array}{l}0.25 \\
0.27 \\
0.27\end{array}$ & $\begin{array}{l}0.41 \\
0.48 \\
0.51\end{array}$ & $\begin{array}{l}0.78 \\
0.69 \\
0.64\end{array}$ \\
\hline 44 & $\begin{array}{c}30 \\
70 \\
150\end{array}$ & $\begin{array}{l}-0.25 \\
-0.31 \\
-0.33\end{array}$ & $\begin{array}{l}0.69 \\
0.63 \\
0.58\end{array}$ & $\begin{array}{l}0.11 \\
0.08 \\
0.07\end{array}$ & $\begin{array}{l}0.75 \\
0.83 \\
0.84\end{array}$ & $\begin{array}{l}0.24 \\
0.19 \\
0.20\end{array}$ \\
\hline 55 & $\begin{array}{c}30 \\
70 \\
150\end{array}$ & $\begin{array}{r}-0.22 \\
-0.35 \\
-0.39\end{array}$ & $\begin{array}{l}0.70 \\
0.52 \\
0.42\end{array}$ & $\begin{array}{l}0.15 \\
0.15 \\
0.12\end{array}$ & $\begin{array}{l}0.71 \\
0.74 \\
0.75\end{array}$ & $\begin{array}{l}0.36 \\
0.48 \\
0.52\end{array}$ \\
\hline 63 & $\begin{array}{c}30 \\
70 \\
150\end{array}$ & $\begin{array}{l}-0.36 \\
-0.44 \\
-0.47\end{array}$ & $\begin{array}{l}0.42 \\
0.26 \\
0.11\end{array}$ & $\begin{array}{l}0.17 \\
0.12 \\
0.06\end{array}$ & $\begin{array}{l}0.63 \\
0.64 \\
0.65\end{array}$ & $\begin{array}{l}0.64 \\
0.71 \\
0.72\end{array}$ \\
\hline \multicolumn{7}{|c|}{ Direction $\varphi=34^{\circ} \mathrm{NE}$} \\
\hline 26 & $\begin{array}{c}30 \\
70 \\
150\end{array}$ & $\begin{array}{c}-0.05 \\
0.31 \\
0.46\end{array}$ & $\begin{array}{l}0.30 \\
0.34 \\
0.33\end{array}$ & $\begin{array}{l}0.61 \\
0.70 \\
0.62\end{array}$ & $\begin{array}{l}-0.36 \\
-0.25 \\
-0.19\end{array}$ & $\begin{array}{l}0.57 \\
0.35 \\
0.27\end{array}$ \\
\hline 44 & $\begin{array}{c}30 \\
70 \\
150\end{array}$ & $\begin{array}{l}0.59 \\
0.71 \\
0.64\end{array}$ & $\begin{array}{l}0.50 \\
0.47 \\
0.46\end{array}$ & $\begin{array}{l}0.44 \\
0.45 \\
0.55\end{array}$ & $\begin{array}{l}-0.02 \\
-0.02 \\
-0.06\end{array}$ & $\begin{array}{l}0.24 \\
0.17 \\
0.20\end{array}$ \\
\hline 55 & $\begin{array}{c}30 \\
70 \\
150\end{array}$ & $\begin{array}{l}0.74 \\
0.83 \\
0.72\end{array}$ & $\begin{array}{l}0.15 \\
0.05 \\
0.04\end{array}$ & $\begin{array}{l}0.53 \\
0.49 \\
0.63\end{array}$ & $\begin{array}{l}-0.12 \\
-0.09 \\
-0.17\end{array}$ & $\begin{array}{l}0.10 \\
0.03 \\
0.03\end{array}$ \\
\hline 63 & $\begin{array}{c}30 \\
70 \\
150\end{array}$ & $\begin{array}{l}0.78 \\
0.77 \\
0.59\end{array}$ & $\begin{array}{r}-0.18 \\
-0.26 \\
-0.23\end{array}$ & $\begin{array}{l}0.48 \\
0.53 \\
0.72\end{array}$ & $\begin{array}{l}-0.10 \\
-0.11 \\
-0.23\end{array}$ & $\begin{array}{l}-0.03 \\
-0.08 \\
-0.11\end{array}$ \\
\hline
\end{tabular}

